\title{
A New Bidirectional Wideband Circularly Polarized Cylindrical Dielectric Resonator Antenna using Modified J-shaped Ground Plane for WiMAX/LTE Applications
}

\author{
Rajkishor KUMAR ${ }^{1}$, Raghvendra Kumar CHAUDHARY ${ }^{2}$ \\ ${ }^{1}$ Dept. of Electronics and Communication Engineering, Koneru Lakshmaiah Education Foundation \\ (formerly K L University), Vaddeswaram, Guntur, 522502, AP, India \\ ${ }^{2}$ Dept. of Electronics Engineering, Indian Institute of Technology (Indian School of Mines), Dhanbad, 826004, India \\ rajkishorkumar88@gmail.com,raghvendra.chaudhary@gmail.com \\ Submitted March 10, 2018 / Accepted February 27, 2019
}

\begin{abstract}
A new singly-fed bidirectional wideband circularly polarized cylindrical dielectric resonator antenna (CDRA) using modified J-shaped ground plane is investigated and presented in this paper. The designed antenna excited by a single microstrip feed line with the modified Jshaped ground plane, which supports the orthogonal mode generation i.e. HEM $11 \delta$ mode for realizing circular polarization (CP). Measured results show that the proposed antenna achieved $S_{11} \leq-10 \mathrm{~dB}$, input impedance bandwidth of $41.44 \%$ (centered at $3.74 \mathrm{GHz}$ ) and 3-dB axial ratio bandwidth in broadside direction of $29.91 \%$ (centered at $3.61 \mathrm{GHz}$ ). The average measured gain and simulated radiation efficiency in broadside are $2.84 \mathrm{dBic}$ and $94.69 \%$ respectively, throughout the working band. The proposed CPDRA is a bidirectional radiator, and the radiation patterns on both sides are nearly the same. The antenna radiates left-handed $C P$ wave in $+z$-direction and right-handed $C P$ wave in -z-direction for both the resonance frequencies, which has been confirmed by plotting $C P$ radiation pattern. The presented design can be used for Wi-MAX (3.3-3.7 GHz) and LTE3400 (3400-3800 MHz) bands.
\end{abstract}

\section{Keywords}

Bidirectional, wideband, circular polarization, dielectric resonator antenna, microstrip feed, J-shaped ground plane

\section{Introduction}

Due to the great demand of antennas having wide bandwidth and consistent far-field properties with low metallic/dielectric losses in modern antenna technology, dielectric resonator antenna (DRA) is very popular among antenna researchers [1] compared to other conventional antennas [2], [3]. DRAs offer a wide range of feeding mechanisms such as a probe, microstrip feed line, aperture coupled etc., which shows their flexibility nature. DRA provides advantages like high radiation efficiency, wide bandwidth, low loss and small size [4], [5] over microstrip antennas. Primarily, DRA is used to design linearly polarized (LP) antennas [6] but in last decade extensive research is going on circularly polarized (CP) antennas [7]. Circular polarization is good for mobile communications as polarization losses due to physical misalignment are avoided [8].

The advantages of DR based circularly polarized antenna over microstrip based circularly polarized antenna are as follows: (i) DRA have negligible conductor loss, so high radiation efficiency has been achieved; (ii) to increase the antenna gain, various types of mode have been excited inside the DR; (iii) flexibility to choose different types of feeding mechanism and shapes of DR so antenna designer can easily choose as per their requirements. There are two design methods reported in DRA to produce circular polarization, the first is single and another is dual/multiple feeding techniques. Extensive literature survey shows that single feeding techniques (SFT) show less axial ratio (AR)bandwidth (3-4\%). However, they offer simple geometry/ construction with compactness [9]. A dual feeding technique (DFT) shows wide AR-bandwidth as compared to SFT but suffers complex geometry and large radiator size [10]. In recent years, antenna engineers focused on wideband circularly polarized DRA by using single feeding techniques which have simple geometry and feeding network [11-16]. It is confirmed from previously published papers that wide AR-bandwidth can be achieved by using a combination of SFT with the modified shape of DRA or combination of the conventional shape of DRA with modified SFT. Example A - SFT with modified shaped DRA: A stair-shaped DRA using SFT with slot excitation achieves $10.6 \% \mathrm{CP}$ bandwidth reported in [11], whereas in [12], a wideband CP having trapezoidal DRA with ARbandwidth of $21.5 \%$ and excited with SFT has been presented. Example B - conventional shape DRA with modified SFT: In [13], a rectangular shape of DRA excited with an extended microstrip feed to acquire $9.2 \%$ of AR-bandwidth, [14] uses aperture slot and modified microstrip feed line to excite the rectangular DRA showing $12.03 \%$ of AR 
bandwidth. Example C - modified SFT with modified shaped DRA: using rotated stair DRA and excited with modified SFT having a slot on the ground plane has been reported with AR-bandwidth of $18.2 \%$ [15], stair-shaped DRA with extended microstrip feed line excitation exhibiting 22\% AR-bandwidth is shown in [16].

In this paper, a new singly-fed wideband circularly polarized cylindrical DRA (CDRA) has been presented and designed for wireless communication system, e.g. WiMAX and LTE3400 band. Parametric studies have been performed to observe the effect of the ground plane on the input reflection coefficient and axial ratio bandwidth. To achieve wide AR-bandwidth in cylindrical DRA, orthogonal modes are required. These orthogonal modes are originated by using the modified J-shaped ground plane. The $\mathrm{HEM}_{11 \delta}$ mode has been excited in CDRA at $3.50 \mathrm{GHz}$. Measured results show that the proposed antenna exhibits 3-dB AR-bandwidth of 29.91\% (3.07-4.15 GHz) in broadside direction and input impedance bandwidth $\left(S_{11}<\right.$ $-10 \mathrm{~dB})$ of $41.44 \%(2.97-4.52 \mathrm{GHz})$. Simple design, low cost, and conventional shape of DRA are the main advantages of the proposed antenna.

\section{Antenna Geometry}

Figure 1 depicts the design structure of the proposed wideband circularly polarized cylindrical DRA (CDRA). The proposed antenna consists of cylindrical DR having radius $D_{\mathrm{r}}$, height $D_{\mathrm{h}}$ and made of alumina material $\left(\varepsilon_{\mathrm{r}}=9.8\right.$ and $\tan \delta=0.002$ ). The DR is loaded on low-cost FR4 glass epoxy substrate having length $L$, width $W$, and height $H_{\mathrm{S}}$ with a dielectric constant $\left(\varepsilon_{\mathrm{r}}\right) 4.4$ and a loss tangent $(\tan \delta)$ 0.025 . The proposed antenna is excited with $50 \Omega$ microstrip feed line etched on the top of a substrate having lengths $L_{\mathrm{S}}, L_{\mathrm{S} 3}$ and width $W_{\mathrm{S}}$. In the bottom side of the sub-

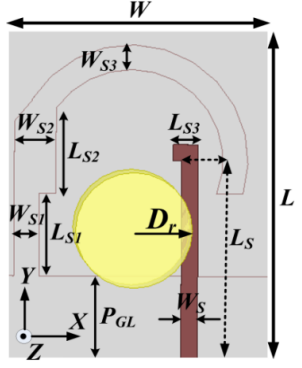

(a)

Cylindrical DR

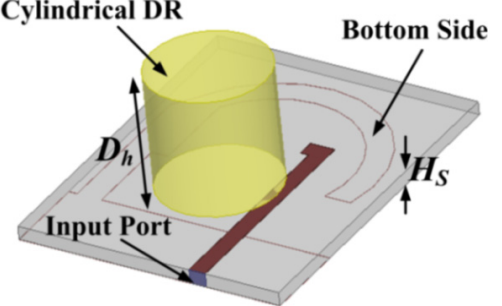

(c)

Fig. 1. Geometry of the proposed wideband circularly polarized CDRA: (a) top view, (b) bottom view, (c) 3D view.

\begin{tabular}{|c|c|c|c|}
\hline Parameters & Values $(\mathrm{mm})$ & Parameters & Values $(\mathrm{mm})$ \\
\hline$D_{\mathrm{r}}$ & 7 & $L_{\mathrm{S} 2}$ & 9 \\
\hline$D_{\mathrm{h}}$ & 14 & $L_{\mathrm{S} 3}$ & 3 \\
\hline$L$ & 40 & $W_{\mathrm{S}}$ & 2 \\
\hline$W$ & 32 & $W_{\mathrm{S} 1}$ & 3 \\
\hline$H_{\mathrm{S}}$ & 1.6 & $W_{\mathrm{S} 2}$ & 5 \\
\hline$L_{\mathrm{S}}$ & 24 & $W_{\mathrm{S} 3}$ & 3 \\
\hline$L_{\mathrm{S} 1}$ & 10 & $P_{\mathrm{GL}}$ & 10 \\
\hline
\end{tabular}

Tab. 1. Optimal design parameters of the proposed CP antenna.

strate, the modified J-shaped ground plane is designed with parameters of $W_{\mathrm{S} 1}, W_{\mathrm{S} 2}, W_{\mathrm{S} 3}, L_{\mathrm{S} 1}$ and $L_{\mathrm{S} 2}$ as shown in Fig. 1(a). The values of the antenna design parameters are shown in Tab. 1.

\section{Operating Principle of Proposed Antenna}

\subsection{Antenna Design Approach}

In this sub-section, the concept of the modified J-shaped ground plane and its design methodology using HFSS 14.0 software has been discussed. Figure 2 shows the possible combination of the ground plane (accordingly named here as Antenna-1, Antenna-2, Antenna-3, and Antenna-4). Antenna-1 to Antenna-4 is designed such that it presents the variations in ground plane dimensions. Rest all the parameters are same in this case i.e., dielectric constant, dimensions (length, width, and height), and shape of DR and FR4 substrate, the length and width of the microstrip feed line. Figure 3 shows the effect of surface current distribution corresponding to different antenna configurations to explain the origin of circular polarization. Figure 4 depicts the results of input impedance bandwidth and AR bandwidth for different combinations of Antenna-1 to Antenna-4. Studies on Antenna-1, 2, 3 and 4 are carried out in the next sub-sections.

Initially, CDRA with a single microstrip feedline with full ground plane has been studied. It is observed from Fig. 3(a) that the surface current distribution is concentrated below the CDRA so that no orthogonal modes are formed. In this case, fields are tightly bounded between the CDRA, feed and ground plane, therefore very small coupling takes place within CDRA. Hence no input impedance bandwidth and AR-bandwidth is observed in Fig. 4.

As discussed in the previous section, the coupling between CDRA and feed is weak due to full ground plane. Further, to overcome this issue the ground plane has been modified as a partial ground plane. This arrangement shows a balanced coupling between the feed-line and CDRA, hence orthogonal modes are found in Fig. 3(b). Antenna-2 shows the input impedance bandwidth $\left(\mathrm{S}_{11} \leq-10 \mathrm{~dB}\right)$ of $34.23 \%$ $(3.08-4.35 \mathrm{GHz})$ and $3-\mathrm{dB}$ AR-bandwidth of $18.65 \%$ (3.65-4.40 GHz) in broadside direction, shown in Fig. 4. 


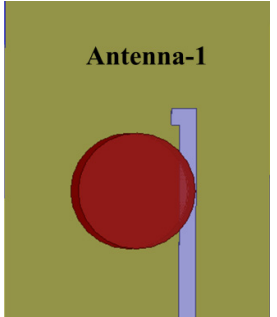

(a)

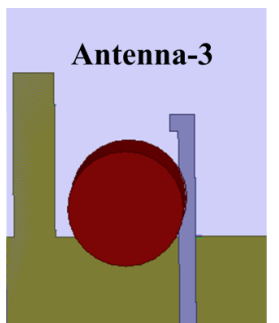

(c)

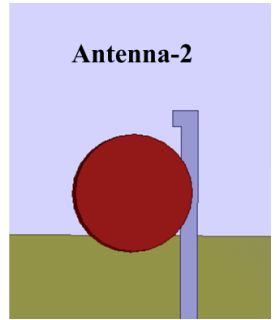

(b)

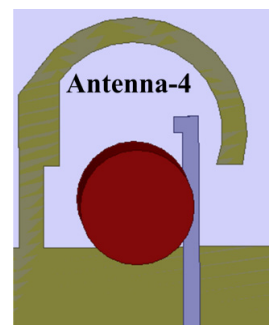

(d)
Fig. 2. Design steps based on the ground plane of the proposed antenna: (a) Antenna-1: Full ground plane. (b) Antenna-2: Only partial ground plane. (c) Antenna-3: Modified partial ground plane. (d) Antenna-4: Modified J-shaped ground plane.

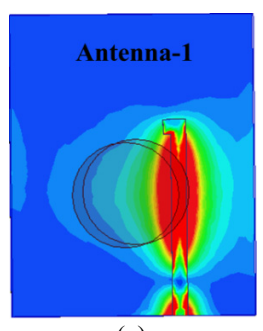

(a)

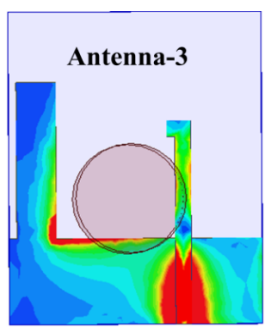

(c)

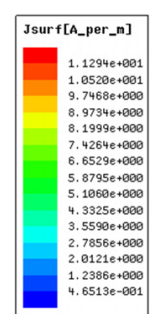

$4.6513 e-2001$

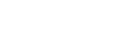

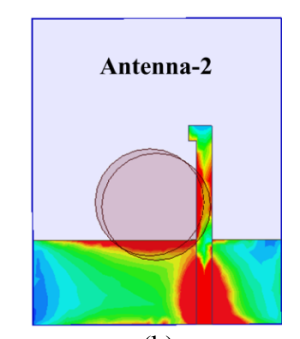

(b)

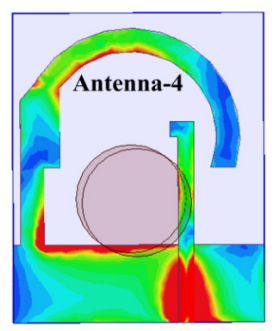

(d)
Fig. 3. Effect of surface current density on the proposed antenna (a) Antenna-1: Full ground plane. (b) Antenna-2: Only partial ground plane. (c) Antenna-3: Modified partial ground plane. (d) Antenna-4: Modified J-shaped ground plane.

For further improvements in input impedance and AR-bandwidth of Antenna-2, the partial ground plane has been modified as shown in Fig. 2(c) and named here as Antenna-3. This antenna design shows perfect matching with input impedance bandwidth $\left(\mathrm{S}_{11} \leq-10 \mathrm{~dB}\right)$ of $37.79 \%$ $(3.09-4.53 \mathrm{GHz})$ but fails to generate orthogonal modes; hence no AR-bandwidth is achieved. However, orthogonality could be seen from surface current distribution at the corner of the modified partial ground plane as shown in Fig. 3(c) but unable to couple properly with CDRA; hence structure did not support the circular polarization as shown in Fig. 4(b).
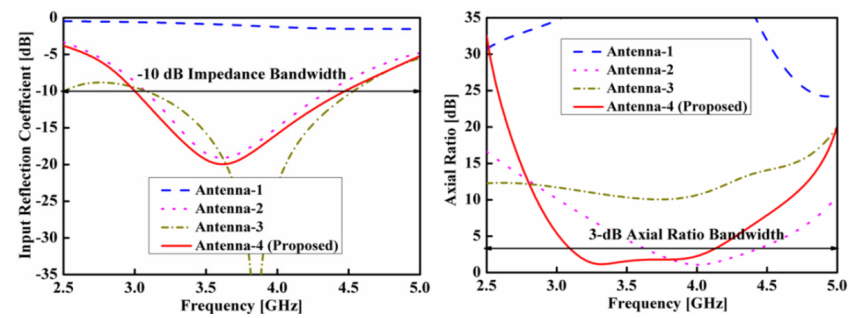

Fig. 4. Effect of different ground plane of the proposed antenna-1 to antenna-4: (a) Input reflection coefficient. (b) AR-bandwidth in broadside direction.

Finally, Antenna-4 with modified J-shaped ground plane has been introduced to improve the AR-bandwidth and input impedance bandwidth as shown in Fig. 2(d). Surface current distribution confirms the balanced coupling as well as the condition of orthogonality as shown in Fig. 3(d). Hence good input impedance matching is observed with input impedance bandwidth $\left(\mathrm{S}_{11} \leq-10 \mathrm{~dB}\right)$ of $39.03 \%(3.01-4.47 \mathrm{GHz})$ and wide AR-bandwidth of $25.28 \%(3.11-4.01 \mathrm{GHz})$ as shown in Fig. 4(a) and 4(b), respectively.

\subsection{Operation of the Arc}

In this sub-section, the operation of arc has been studied to achieve the optimal value of the AR-bandwidth in broadside direction. Here, the arc is mainly responsible for the providing the $\lambda / 4$ path delay between the two orthogonal electric field lines which is turned to generate circular polarization characteristics in the proposed antenna configuration, as shown in Fig. 5 and Fig. 6.

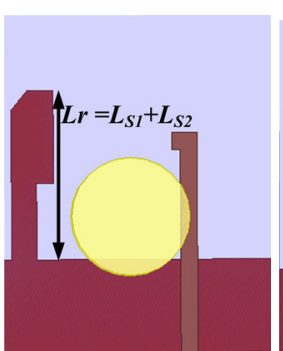

(a)

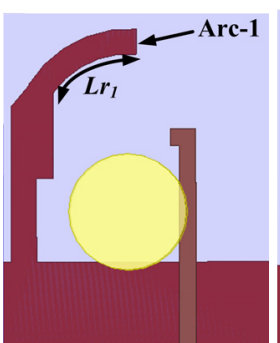

(b)

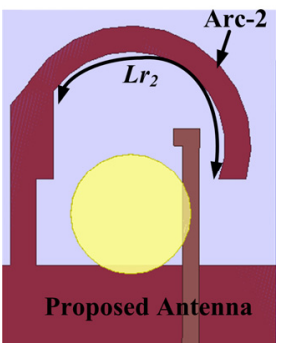

(c)
Fig. 5. Different configuration of arc operation to generate orthogonal modes: (a) No arc, (b) Arc-1, $L \mathrm{r}_{1}=10 \mathrm{~mm}$, (c) Arc-2, $L r_{2}=22 \mathrm{~mm}$.

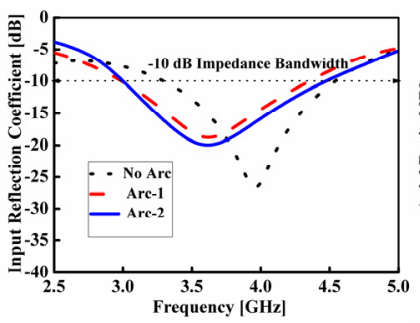

(a)

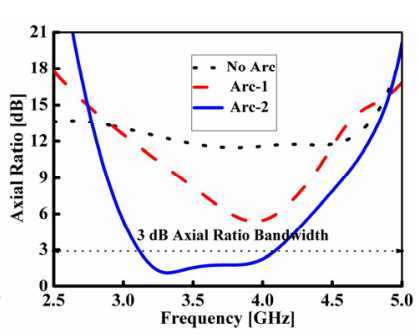

(b)
Fig. 6. Effect of variation of arc on antenna performance: (a) Input reflection coefficient. (b) AR-bandwidth in broadside direction. 
Figure 6(a) shows the input impedance bandwidth of the antenna configurations in different arc length. It is observed from Fig. 6(a) that the -10-dB impedance bandwidth of different arc configurations is approximately the same. Figure 6(b) depicts the AR-bandwidth variation versus frequency with change in the arc length of the bent microstrip line i.e., Arc-1 $\left(\operatorname{Lr}_{2}\right)$ and Arc-2 $\left(\operatorname{Lr}_{2}\right)$. It can be observed from Fig. 6(b) that if the length of the bent microstrip line increases i.e., Arc-1 becomes Arc-2, the value of AR bandwidth increases. It confirmed that the bent microstrip line i.e., Arc-2 $\left(\mathrm{Lr}_{2}=0.26 \lambda\right)$ provides approximately $\lambda / 4$ path delay at $3.60 \mathrm{GHz}$ compared to Arc-1 $\left(L \mathrm{r}_{1}=\right.$ $0.12 \lambda)$. Therefore, Arc-2 is mainly responsible for the generation of orthogonal field components in the proposed antenna (Phase Shift $=2 \pi / \lambda$ Path Delay) [17] and satisfies the necessary condition for the obtaining circular polarization.

\subsection{Stub on the Right from the Resonator (Top View)}

Stub on the right from the resonator (top view) has also been studied, as shown in Fig. 7. It is observed that the microstrip line with stub and without stub affects the ARbandwidth as well as the input impedance bandwidth, as shown in Fig. 8. It is found from Figs. 8(a) and 8(b) that the stub gives the improvement of $-10 \mathrm{~dB}$ impedance bandwidth and AR-bandwidth compared to the simple microstrip line coupling. It happens due to the enhancement of coupling between cylindrical DRA and microstrip line with a stub.

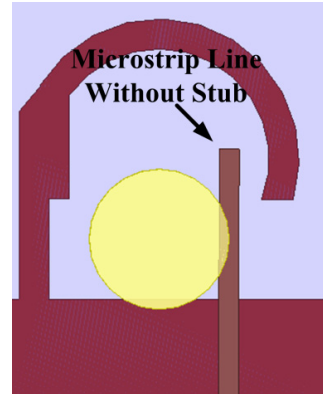

(a)

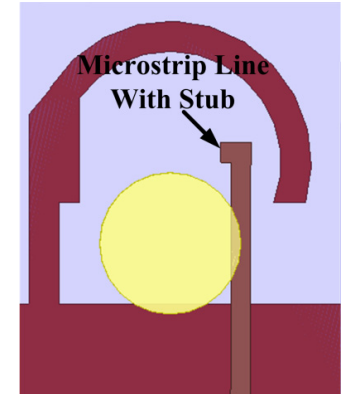

(b)
Fig. 7. Effect of the microstrip line on antenna performance: (a) Without Stub, (b) With Stub.

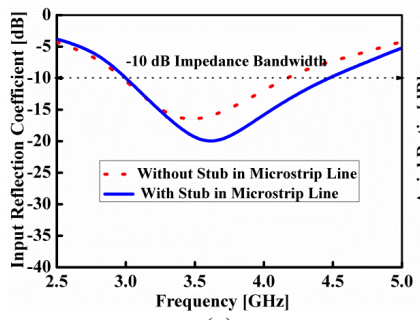

(a)

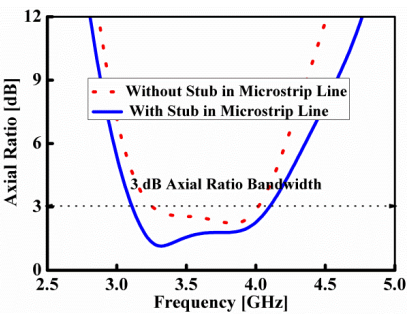

(b)
Fig. 8. Simulated results of with and without stub microstrip line: (a) Input reflection coefficient. (b) AR-bandwidth in broadside direction.

\section{Parametric Study and Validation of CP}

Parametric studies have been performed for the proposed antenna to examine the performance with varying antenna design parameters. EM wave simulator Ansoft HFSS 14.0 software package has been used for simulation studies.

\subsection{Effect of Variation in Dielectric Constant}

The variations of dielectric constant and its effect on impedance and AR-bandwidth has been discussed and shown in Fig. 9. It has been observed in Fig. 9(a) that if dielectric constant increases, input impedance bandwidth decreases from $39.50 \%$ to $34.90 \%$ and resonance frequency shifted to lower frequency range due to dielectric constant increment. The dielectric constant significantly influences the 3-dB AR-bandwidth positively. If the dielectric constant is varied from 6 to 14 then the AR-bandwidth increased from $22.24 \%$ to $30.02 \%$ as shown in Fig. 9(b).

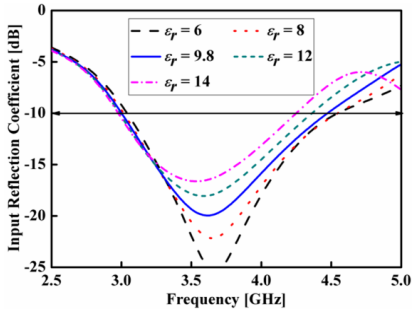

(a)

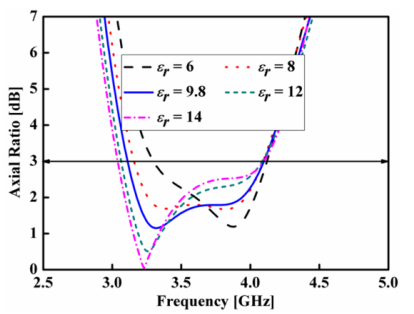

(b)
Fig. 9. Effect of variation of CDRA dielectric constant: (a) Input reflection coefficient. (b) AR-bandwidth in broadside direction.

\subsection{Effect of CDRA Radius $\left(D_{r}\right)$}

In this sub-section, a variation of CDRA radius and its effect on impedance and AR-bandwidth are discussed. From Fig. 10(a), impedance mismatch has been found due to coupling variations among CDRA and the modified $\mathrm{J}$-shaped ground. This results in degradation of input impedance bandwidth from $35.90 \%$ to $19.13 \%$ with increased CDRA radius from $5 \mathrm{~mm}$ to $9 \mathrm{~mm}$. The AR-bandwidth in broadside direction is shown in Fig. 10(b), where orthogonal

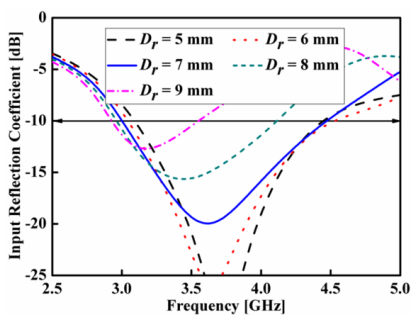

(a)

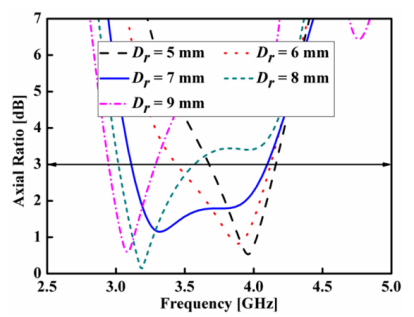

(b)
Fig. 10. Effect of variation of CDRA radius: (a) Input reflection coefficient. (b) AR-bandwidth in broadside direction. 
modes have been generated in all conditions $\left(D_{\mathrm{r}}=5 \mathrm{~mm}\right.$ to $D_{\mathrm{r}}=9 \mathrm{~mm}$ ). But in $7 \mathrm{~mm}$ case, proper orthogonal modes are generated that maximizes AR-bandwidth to 25.28\% (3.11-4.01 GHz), whose frequency range also falls within the input impedance bandwidth.

\subsection{Validation of CP in CDRA}

To understand CP radiation generation from the proposed antenna, the simulated (HFSS 14.0) electric fields distribution inside the CDRA has been shown in Fig. 11 at $3.50 \mathrm{GHz}$. The circular polarization has been verified by plotting field distributions at different phases $0^{\circ}, 90^{\circ}, 180^{\circ}$ and $270^{\circ}$. At phase $0^{\circ}$, vector field distribution of CDRA has rotated in counter clockwise direction as shown in Fig. 11(a). At phase $90^{\circ}$, it is observed that vector field distribution rotated in a clockwise direction, as shown in Fig. 11(b). Based on these two results, it can be concluded that orthogonal modes have been generated at $3.50 \mathrm{GHz}$ to realize the circular polarization. The centered frequency of the proposed antenna is chosen such that AR-bandwidth is below 3-dB. From the orientation of E-field at $3.62 \mathrm{GHz}$, it has been observed that $\mathrm{HEM}_{11 \delta}$ mode is excited inside CDRA as shown in Fig. 12.

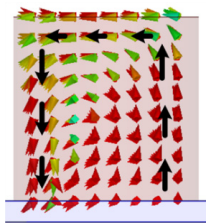

(a)

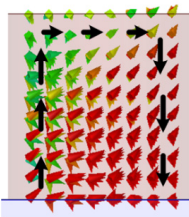

(b)

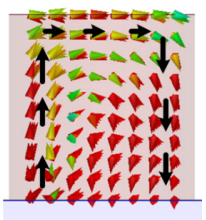

(c)

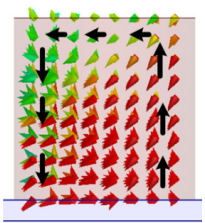

(d)

Fig. 11. Simulated E-field distribution inside the CDRA at $3.50 \mathrm{GHz}$ : (a) E-field, phase $0^{\circ}$; (b) E-field, phase $90^{\circ}$; (c) E-field, phase $180^{\circ}$; (d) E-field, phase $270^{\circ}$.

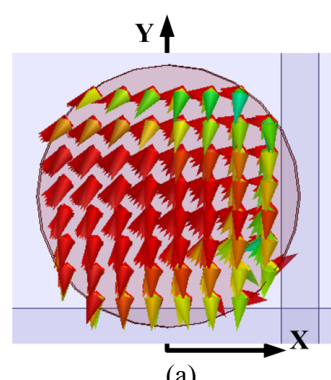

(a)

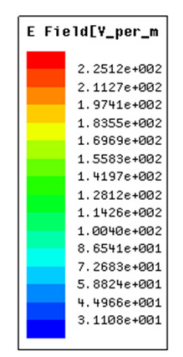
$4966 e+081$
$1108 e+001$

Fig. 12. E-field distributions on CDRA to confirm the $\mathrm{HEM}_{11}$ mode at $3.50 \mathrm{GHz}$ : (a) top view, (b) side view.

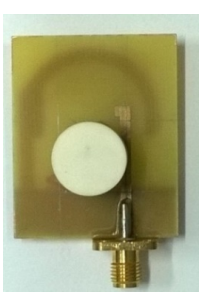

(a)

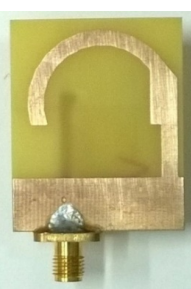

(b)

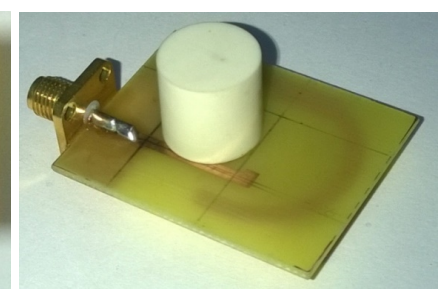

(c)
Fig. 13. Fabricated wideband circular polarization CDRA: (a) top view, (b) modified J-shaped ground plane, (c) $3 \mathrm{D}$ view.

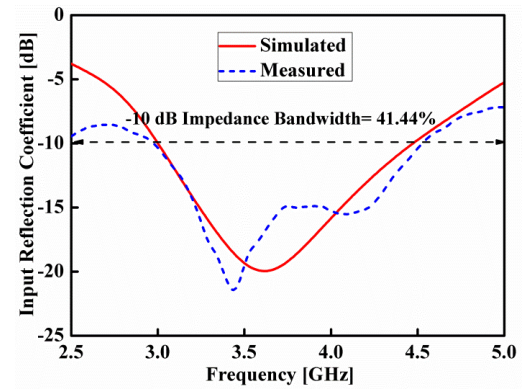

Fig. 14. Simulated and measured input reflection coefficient of the proposed wideband CP CDRA.

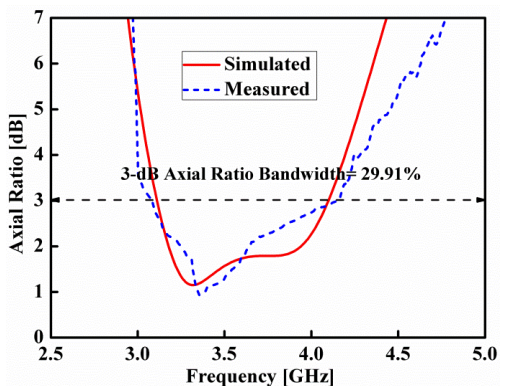

Fig. 15. Simulated and measured AR-bandwidth of the proposed wideband CP CDRA in broadside direction.

\section{Experimental Results and Discussion}

To validate the simulation results, a prototype antenna has been designed and implemented as shown in Fig. 13. The input reflection coefficient has been measured by using an E5071C Agilent vector network analyzer. Figure 14 illustrates the input reflection coefficient of the proposed antenna where simulated and measured input impedance bandwidths $\left(\mathrm{S}_{11} \leq-10 \mathrm{~dB}\right)$ are $39.03 \%(3.01-4.47 \mathrm{GHz})$ and $41.44 \%(2.97-4.52 \mathrm{GHz})$ respectively.

The measurement of AR-bandwidth has been done by using a high gain rotated rectangular horn antenna as a source and our proposed antenna as a receiver. The electric fields in two orientations, $E_{\theta}$ and $E_{\varphi}$ are measured in $\mathrm{RF}$ anechoic chamber [18]. After that, the collected data has been used in the given formula [19], for finding the AR bandwidth. The simulated and measured 3-dB AR-bandwidth in broadside direction $\left(\theta=0^{\circ}, \Phi=0^{\circ}\right)$ are $25.28 \%$ $(3.11-4.01 \mathrm{GHz})$ and $29.91 \%(3.07-4.15 \mathrm{GHz})$ respectively as shown in Fig 15.

Usable bandwidth of the proposed antenna should be considered such that both input reflection coefficient and AR-bandwidths are in an acceptable range. Therefore the percentage of simulated input reflection coefficient bandwidth and AR-bandwidth remains same whose value is $25.28 \%(3.11-4.01 \mathrm{GHz})$, whereas their measured value is $29.91 \%(3.07-4.15 \mathrm{GHz})$. The reason for getting both wide input impedance bandwidth $\left(\mathrm{S}_{11} \leq-10 \mathrm{~dB}\right)$ and wide $3-\mathrm{dB}$ AR-bandwidth are due to introducing modified J-shaped ground plane as shown in Figs. 2(d) and 5(c). Figure 3(d) shows the simulated surface current distribution to explain the above claims. 


\begin{tabular}{|c|c|c|c|c|c|c|c|c|c|c|}
\hline \multirow[b]{2}{*}{$\begin{array}{l}\text { S. } \\
\text { No. }\end{array}$} & \multicolumn{10}{|c|}{ Wideband Circularly Polarized DRA } \\
\hline & Shape of DR & Types of feed & $\varepsilon_{\mathrm{r}}$ & $\begin{array}{c}f_{0} \\
\mathrm{GHz}\end{array}$ & $\begin{array}{l}-10 \mathrm{~dB} \\
\mathrm{BW} \\
(\%)\end{array}$ & $\begin{array}{c}\text { 3-dB } \\
\text { ARBW } \\
(\%)\end{array}$ & $\begin{array}{l}\text { Gain } \\
(\mathrm{dBic})\end{array}$ & $\begin{array}{l}\text { Volume } \\
\text { of DR } \\
\left(\mathrm{mm}^{3}\right)\end{array}$ & Polarization & Ref. \\
\hline 1. & Rotated-Stair & $\begin{array}{c}\text { Single } \\
\text { (aperture coupled) }\end{array}$ & 9.8 & 5.5 & 31 & 18.2 & 4.5 & 1690 & LHCP & [15] \\
\hline 2. & Stair & $\begin{array}{l}\text { Single(extended } \\
\text { microstrip feed) }\end{array}$ & 10.2 & 6 & 37 & 22 & 5.1 & 890 & RHCP & [16] \\
\hline 3. & Spidron-Fractal & $\begin{array}{c}\text { Single } \\
\text { (aperture coupled) }\end{array}$ & 10 & 5 & 37.29 & 11.57 & 2.68 & - & LHCP & [20] \\
\hline 4. & T-shaped & $\begin{array}{c}\text { Dual } \\
\text { microstrip-fed stubs }\end{array}$ & 9.8 & 5.5 & 22.1 & 17.9 & 3.05 & 380 & RHCP/LHCP & [21] \\
\hline 5. & Cylindrical & $\begin{array}{c}\text { Multiple } \\
\text { (Phase-Delay-Line Load) }\end{array}$ & 10 & 2.6 & 34 & 24.2 & 6.5 & 20417 & RHCP & [22] \\
\hline 6. & Cubical & $\begin{array}{c}\text { Single } \\
\text { (Question mark shaped } \\
\text { microstrip feed) }\end{array}$ & 9.8 & 3.29 & 35.35 & 20.62 & 1.51 & 5832 & LHCP & [23] \\
\hline 7. & Cylindrical & $\begin{array}{c}\text { Single } \\
\text { (microstrip feed) }\end{array}$ & 9.8 & 3.75 & 41.44 & 29.91 & 3.57 & 2155 & $\begin{array}{c}\text { Dual } \\
\text { LHCP/RHCP }\end{array}$ & $\begin{array}{c}\text { Proposed } \\
\text { Work }\end{array}$ \\
\hline
\end{tabular}

Tab. 2. Comparison of the proposed antenna with earlier published work.

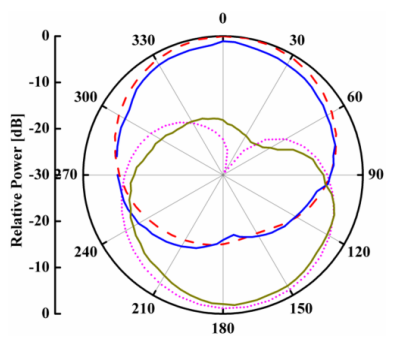

(a)

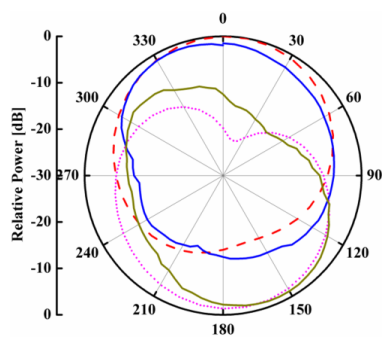

(c)

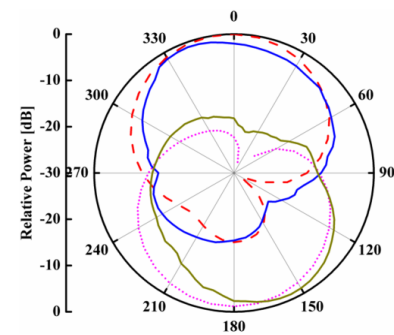

(b)

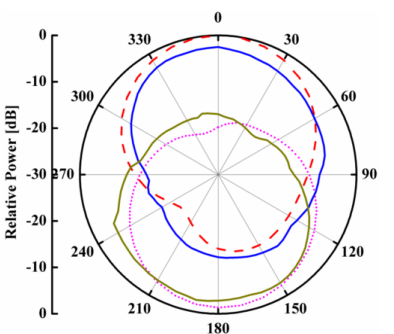

(d)

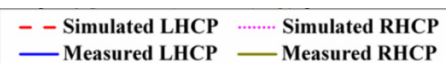

Fig. 16. Simulated and measured bidirectional CP radiation patterns of the proposed antenna: (a) xz-plane at $3.25 \mathrm{GHz}$, (b) yz-plane at $3.25 \mathrm{GHz}$, (c) xz-plane at $3.75 \mathrm{GHz}$, (d) yz-plane at $3.75 \mathrm{GHz}$.

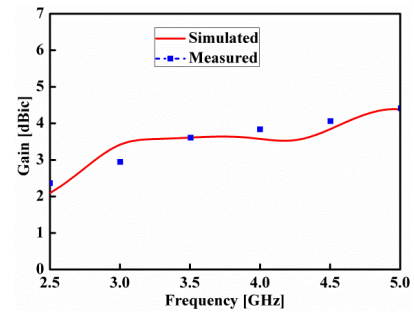

(a)

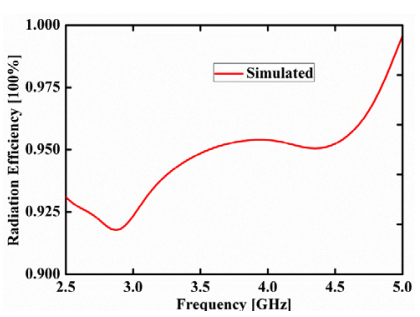

(b)
Fig. 17. Gain and radiation efficiency of the proposed wideband CP DRA in broadside direction $\left(\theta=0^{\circ}, \Phi=0^{\circ}\right)$ (a) Simulated and measured gain. (b) Simulated radiation efficiency.
Figure 16 depicts the radiation pattern in left-hand circular polarization (LHCP) and right-hand circular polarization (RHCP) in $x z$ - and $y z$-planes at $3.25 \mathrm{GHz}$ and $3.75 \mathrm{GHz}$, respectively. The proposed CPDRA is a bidirectional radiator, and the radiation patterns on both sides are nearly the same. The designed antenna radiates the LHCP wave in $+z$-direction and RHCP wave in $-z$-direction for both the resonance frequencies, which has been confirmed by plotting $\mathrm{CP}$ radiation pattern. The difference between the two field components i.e. LHCP and RHCP is $-22.26 \mathrm{~dB}$ at $3.25 \mathrm{GHz}$ and $-19.78 \mathrm{~dB}$ at $3.75 \mathrm{GHz}$, in broadside direction i.e., in $+z$-direction, whereas in $-z$-direction, the RHCP is dominated by LHCP and the difference between RHCP and LHCP is $-14.01 \mathrm{~dB}$ at $3.25 \mathrm{GHz}$ and $-12.51 \mathrm{~dB}$ at $3.75 \mathrm{GHz}$, respectively. The designed antenna shows an average measured gain of $2.84 \mathrm{dBic}$ in broadside direction, as shown in Fig. 17(a). Figure 17(b) shows the proposed antenna's average radiation efficiency of $94.68 \%$ in the working band $(2.97-4.52 \mathrm{GHz})$.

Table 2 shows the comparison of earlier published research work with the proposed antenna. The presented antenna shows more advantages such as bidirectional $\mathrm{CP}$ properties, a wide range of $-10 \mathrm{~dB}$ input impedance bandwidth and 3-dB AR-bandwidth, which is obtained by using a single feeding technique with conventional shape of DR as compared with previously published work. In addition, basic shape, simple feeding technique, the new shape of the ground plane and easy fabrication process to support the various wireless communication systems are another advantages of this proposed design.

\section{Conclusion}

In this paper, a new singly fed bidirectional wideband circularly polarized cylindrical DRA with a modified 
J-shaped ground plane has been investigated. Modified J-shaped ground plane provides optimal coupling to the CDRA and it is also responsible to create orthogonal modes in CDRA. Therefore, the proposed antenna shows wide impedance and axial ratio bandwidths. $\mathrm{HEM}_{11 \delta}$ mode has been investigated by theoretical analysis and verified by rotation of E-fields in CDRA. It is observed from the $\mathrm{CP}$ radiation pattern that the proposed antenna shows lefthand circular polarization (LHCP) in $+z$-direction whereas it shows right-handed $\mathrm{CP}$ in $-z$-direction. Measured $3-\mathrm{dB}$ AR-bandwidth has been found that 29.91\% (3.07-4.15 GHz) in broadside direction with left-hand circular polarization. Gain and radiation efficiency of the proposed antenna has been stable throughout the operating band. The proposed antenna is appropriate for wireless communication systems such as Wi-MAX and LTE3400 (3400-3800 MHz) applications.

\section{References}

[1] LUK, K. M., LEUNG, K. W. Dielectric Resonator Antenna. Research Studies Press, U. K., 2003. ISBN: 086380263 X

[2] PALANDOKEN, M. Artificial Materials based Microstrip Antenna Design. Ch. 3 in NASIMUDDIN, N. (ed.) Microstrip Antennas. InTech Europe, 2011. ISBN: 978-953-307-247-0

[3] PALANDOKEN, M. Dual broadband antenna with compact double ring radiators for IEEE $802.11 \mathrm{ac} / \mathrm{b} / \mathrm{g} / \mathrm{n}$ WLAN communication applications. Turkish Journal of Electrical Engineering \& Computer Sciences, 2017, vol. 25, p. 1326-1333. DOI: $10.3906 /$ elk-1507-121

[4] PETOSA, A. Dielectric Resonator Antenna Handbook. London (UK): Artech House, 2007. ISBN: 9781596932067

[5] MONGIA, R. K., BHARTIA, P. Dielectric resonator antennas a review and general design relations for resonant frequency and bandwidth. International Journal of Microwave and MillimeterWave Computer-Aided Engineering, 1994, vol. 4, no. 3, p. 230-247. DOI: $10.1002 /$ mmce. 4570040304

[6] CHAUDHARY, R. K., KUMAR, R., SRIVASTAVA, K. V. Wideband ring dielectric resonator antenna with annular-shaped microstrip feed. IEEE Antennas and Wireless Propagation Letters, 2013, vol. 12, p. 595-598. DOI: 10.1109/LAWP.2013.2260317

[7] KUMAR, R., CHAUDHARY, R. K. Modified microstrip-line-fed rectangular dielectric resonator antenna coupled with slotted ground plane for wideband circular polarization. Microwave and Optical Technology Letters, 2016, vol. 58, no. 1, p. 206-210. DOI: $10.1002 / \operatorname{mop} .29523$

[8] GAO, S., LUO, Q., ZHU, F. Circularly Polarized Antennas. West Sussex (U.K.): Wiley, 2014. ISBN: 9781118374412

[9] HUANG, C. Y., WU, J. Y., WONG, K. L. Cross-slot-coupled microstrip antenna and dielectric resonator antenna for circular polarization. IEEE Transactions on Antennas and Propagation, 1999, vol. 47, no. 4, p. 605-609. DOI: 10.1109/8.768798

[10] KHOO, K.-W., GUO, Y.-X., ONG, L. C. Wideband circularly polarized dielectric resonator antenna. IEEE Transactions on Antennas and Propagation, 2007, vol. 55, no. 7, p. 1929-1932. DOI: 10.1109/TAP.2007.900241

[11] CHAIR, R., YANG, S. L. S., KISHK, A. A., et al. Aperture fed wideband circularly polarized rectangular stair shaped dielectric resonator antenna. IEEE Transactions on Antennas and
Propagation, 2006, vol. 54, no. 4, p. 1350-1352. DOI: 10.1109/TAP.2006.872665

[12] PAN, Y., LEUNG, K. W. Wideband circularly polarized trapezoidal dielectric resonator antenna. IEEE Antennas and Wireless Propagation Letters, 2010, vol. 9, p. 588-591. DOI: 10.1109/LAWP.2010.2053910

[13] CHOWDHURY, R., CHAUDHARY, R. K. Circularly polarized rectangular dielectric resonator antenna fed with unequal parallel microstrip lines for Wi-MAX applications. Microwave and Optical Technology Letters, 2017, vol. 59, no. 5, p. 1182-1188. DOI: 10.1002/mop.30492

[14] KUMAR, R., KUMAR CHAUDHARY, R. Circularly polarized rectangular DRA coupled through orthogonal slot excited with microstrip circular ring feeding structure for Wi-MAX applications. International Journal of $R F$ and Microwave Computer-Aided Engineering, 2018, vol. 28, no. 1, p. 1-7. DOI: 10.1002/mmce. 21153

[15] WANG, K. X., WONG, H. A circularly polarized antenna by using rotated-stair dielectric resonator. IEEE Antennas and Wireless Propagation Letters, 2015, vol. 14, p. 787-790. DOI: 10.1109/LAWP.2014.2385475

[16] FAKHTE, S., ORAIZI, H., KARIMIAN, R., et al. A new wideband circularly polarized stair-shaped dielectric resonator antenna. IEEE Transactions on Antennas and Propagation, 2015, vol. 63, no. 4, p. 1828-1832. DOI: 10.1109/TAP.2015.2392131

[17] BALANIS, C. A. Antenna Theory: Analysis and Design. 3rd ed. Hoboken (NJ): John Wiley \& Sons, 2005. ISBN: 0-471-66782-X

[18] TOH, B. Y., CAHILL, R., FUSCO, V. F. Understanding and measuring circular polarization. IEEE Transactions on Education, 2003, vol. 46, no. 3, p. 313-318. DOI: 10.1109/TE.2003.813519

[19] YANG, S. L. S., CHAIR, R., KISHK, A. A., et al. Study on sequential feeding networks for subarrays of circularly polarized elliptical dielectric resonator antenna. IEEE Transactions on Antennas and Propagation, 2007, vol. 55, no. 2, p. 321-333. DOI: 10.1109/TAP.2006.889819

[20] ALTAF, A., YANG, Y., LEE, K. Y., et al. Circularly polarized Spidron fractal dielectric resonator antenna. IEEE Antennas and Wireless Propagation Letters, 2015, vol. 14, p. 1806-1809. DOI: 10.1109/LAWP.2015.2427373

[21] LU, L., JIAO, Y.-C., LIANG, W., et al. A novel low-profile dual circularly polarized dielectric resonator antenna. IEEE Transactions on Antennas and Propagation, 2016, vol. 64, no. 9, p. 4078-4083. DOI: 10.1109/TAP.2016.2574882

[22] SUN, Y.-X., LEUNG, K. W., MAO, J.-F. Dualfunction dielectric resonator as antenna and phase-delay-line load: designs of compact circularly polarized/differential antennas. IEEE Transactions on Antennas and Propagation, 2018, vol. 66, no. 1, p. 414-419. DOI: 10.1109/TAP.2017.2767819

[23] KUMAR, R., CHAUDHARY, R. K. A wideband circularly polarized cubic dielectric resonator antenna excited with modified microstrip feed. IEEE Antennas and Wireless Propagation Letters, 2016, vol. 15, p. 1285-1288. DOI: 10.1109/LAWP.2015.2504840

\section{About the Authors ...}

Rajkishor KUMAR was born in West-Champaran (Bettiah), Bihar, India. He did his Ph.D. from RF \& Microwave Engineering at the Department of Electronics Engineering, Indian Institute of Technology (Indian School of Mines), 
Dhanbad, India, Jan. 2019, and B. E. degree in Electronics and Communication Engineering from Nagpur University, Nagpur, India, 2012. He is currently working as an Assistant Professor at the Department of Electronics and Communication Engineering, Koneru Lakshmaiah Education Foundation (formerly K L University), Vaddeswaram, Guntur, Andhra Pradesh, India. He has authored/co-authored more than 34 referred journal and conference papers and received fellowship from MHRD, Government of India during $\mathrm{Ph}$.D. He was the recipient of the International Travel Grant form DST (SERB) International Travel Support (ITS) Scheme, India. He is a student member of IEEE and reviewer of journals such as IEEE Antenna \& Wireless Propagation Letters, IEEE Access, IET Microwaves, Antennas \& Propagation, IET Electronics Letter, IET The Journal of Engineering, Microwave Optical Technology Letters, AEU-International Journal of Electronics and Communications, ETRI Journal, Wiley Journals, and International Journal of RF and Microwave Computer-Aided Engineering. His current research interests include dielectric resonator, microstrip, metamaterial, substrate integrated waveguide (SIW) antennas, MIMO technology, and RF energy harvesting systems.
Raghvendra Kumar CHAUDHARY (corresponding author) is working as an Assistant Professor at the Department of Electronics Engineering, Indian Institute of Technology (Indian School of Mines), Dhanbad, India. He did his Ph.D. from the Indian Institute of Technology Kanpur, India in Jan. 2014, the M.Tech. degree from the Indian Institute of Technology (BHU), Varanasi, India, in 2009 and the B.Tech. degree from the University Institute of Engineering and Technology, Kanpur India, in 2007. Dr. Chaudhary has authored more than 185 referred journal and conference papers. He was the recipient of the International Travel Grant form CSIR, DST and IIT Kanpur, India. He was the recipient of the Best Student Paper Bronze Award at IEEE APACE, Malaysia in 2010 and also recipient of the Best Paper Award at ATMS, India in 2012. He is member of IEEE and potential reviewer of many journals and conferences such as IEEE Transactions on Antennas \& Propagation, IEEE AWPL, IET MAP, IET Electronics Letters etc. His current research interests involve metamaterials, dielectric resonators, and computational electromagnetics. He is presently handling many research projects in the capacity of Principal Investigator sponsored from Indian funding agencies like SERB (DST), ISRO etc. 